\section{Intralenticular opacification of hydrophilic acrylic intraocular lenses}

MU Saeed, AJ Jafree and R de Cock

\begin{abstract}
Purpose To find out the incidence of intraocular lens (IOL) optic opacification in a suspect IOL.

Methods Retrospective review of patients'

notes 3-4 years postimplant.

Results In all, 56 IOLs showed signs of opacification, resulting in reduced vision out of 181 lenses traced.

Conclusion Certain hydrophilic acrylic IOLs like the model in question (SC60B-0UV) show opacification of the IOL, which may impair the vision of pseudophakic patients. However, not all lenses of this variety exhibit this cloudiness. Factors affecting this phenomenon are not yet completely clear but may include changes in the UV absorbant material incorporated in the lens substance itself. We report a series of patients who had received this lens and experienced loss of vision due to opacification of the IOL. In a follow-up ranging from 1 to 4 years postoperatively, a higher incidence of postoperative opacification of this lens emerges, after comparison with existing literature. IOL exchange in such patients is the only option. However, this mode of treatment should not be offered lightly as results may be guarded at best even in the face of a technically satisfactory procedure.

Eye (2005) 19, 661-664. doi:10.1038/sj.eye.6701621

Published online 3 September 2004
\end{abstract}

Keywords: intraocular lens clouding; SC-60OUV; hydrophilic acrylic lens; intraocular lens exchange; loss of visual acuity

\section{Introduction}

Intraocular lens (IOL) implants have undergone considerable evolution in design and material since the time of the first IOL implantation by Harold Ridley in 1949. This reflects the continuing search for a lens implant that is well tolerated by the eye, relatively easy (and therefore safe) to position correctly through small incisions, and sufficiently economical to allow high-volume use in those parts of the world with the highest rates of cataract blindness.

With the large number of IOL styles currently available the decision as to which lens to implant, apart from prevailing intraoperative conditions, often depends on a balance of surgeon preference and cost. At a time when surgeons in our department were using either the foldable three-piece hydrophobic acrylic IOL (Acrysof, Alcon) or rigid one-piece all PMMA posterior chamber lenses, a flexible hydrophilic acrylic lens was presented as an alternative that provided ease of insertion combined with greater tissue biocompatibility. This was this SC-60B-0UV (DGR incorporated, Medical Developmental Research, Inc., USA) in which we, as previously reported by others, noted a high incidence of postoperative opacification. ${ }^{1}$ This report presents a retrospective assessment of this complication 4 years after surgery.

\section{Methods and materials}

A retrospective study of notes of patients receiving the SC-60-0UV lens was carried out 4 years postoperatively. Ethical approval to review notes and carry out the study was obtained. Patients were identified from theatre books and notes were reviewed. Data were collected on preagreed audit forms. Parameters collected included visual acuity (preoperatively, postoperatively, and at last visit), ocular comorbidity patterns, presence or absence of any intralenticular opacification, posterior capsular opacification, and YAG capsulotomy, etc in both the involved eye and the contralateral eye. A note was made of cataract
Department of Ophthalmology William Harvey Hospital Willesborough Ashford

Kent, UK

Correspondence: MU Saeed Department of Ophthalmology Clarendon Wing Leeds General Infirmary Leeds, UK

Tel.: + 447939905966

Fax: + 441132926239

E-mail: musmansaeed@ aol.com

Received: 2 December 2003 Accepted: 20 April 2004 Published online: 3 September 2004 
or pseudophakia in the contralateral eye with the lens type and presence of subsequent lens or posterior capsular opacification. Surgical complications at the time of primary surgery were noted as well. Loss of vision in our patients with intralenticular opacification was calculated by recording the best-corrected visual acuity after discharge and the best-corrected visual acuity after the onset of lenticular opacification at the last visit. The number of Snellen lines lost was thus calculated (Reference Figure 3).

\section{Results}

A notes retrieval rate of $90.4 \%$ was achieved, which involved records of 181 eyes of 165 patients, who had received the SC-60B-0UV IOL following phacoemulsification. In all, 90 right eyes and 91 left eyes were involved. A total of 16 patients received the lenses in both eyes. In all, $35 \%$ of patients were male, $65 \%$ of patients were female with an average age of 76.5 years (range 29-96 years). At the time of data collection, 32 patients had died and were lost to further follow-up. Average age of deceased patients was 83.3 years (range 65-96 years). The time of death was variable among patients with a range of 1 to 38 months postoperatively (average 17.6 months).

In addition to cataract, $33 \%$ of patients had age-related macular degeneration, $17.6 \%$ had glaucoma, $5.5 \%$ had diabetic retinopathy, and in $0.5 \%$ there was a history of uveitis. In all, $30.8 \%$ eyes did not have any other preoperative evidence of ocular comorbidity other than a cataract.

In 56 eyes (30.9\%), the SC-60B-0UV implant was noted at the slit lamp to have some degree of opacification in the optic of the IOL including two patients who had died. Of the 16 patients who had bilateral implantation of the SC-60B-0UV lens ${ }^{\mathrm{TM}}$, seven were recorded to have opacification of lens in at least one of the lenses (Figure 1). In two patients, opacification of the lens optic was observed bilaterally. The degree of cloudiness in most cases was not further specified. Lens opacification was noted to occur across the whole spectrum of lens powers (Figure 2).

In all, 22 eyes (12\%) had PCO together with opacification of the intraocular lens implant. A further 23 eyes $(13 \%)$ were observed to have posterior capsular opacification without any change in the lens optic.

On average 2.1 Snellen lines were lost per patient following IOL opacification but the range of Snellen acuity change was widely varied between 0 and 7 lines of Snellen visual acuity (Figure 3). Patients with a recorded opacification of the IOL were asymptomatic in six instances (10.7\%) but a majority (89.2\%) noticed a drop in their visual status.

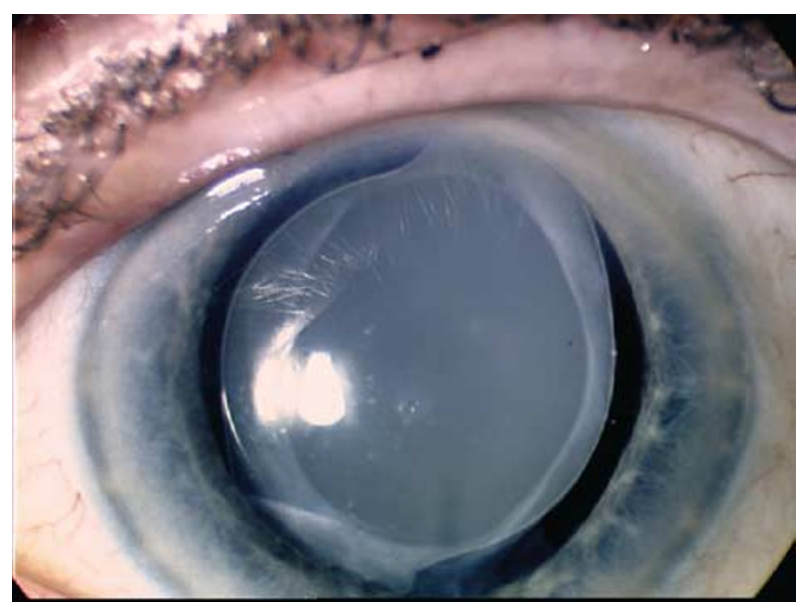

Figure 1 An opacified SC60B-0UV intraocular lens 'in the bag'.

\section{Total lenses implanted versus opaque lenses}

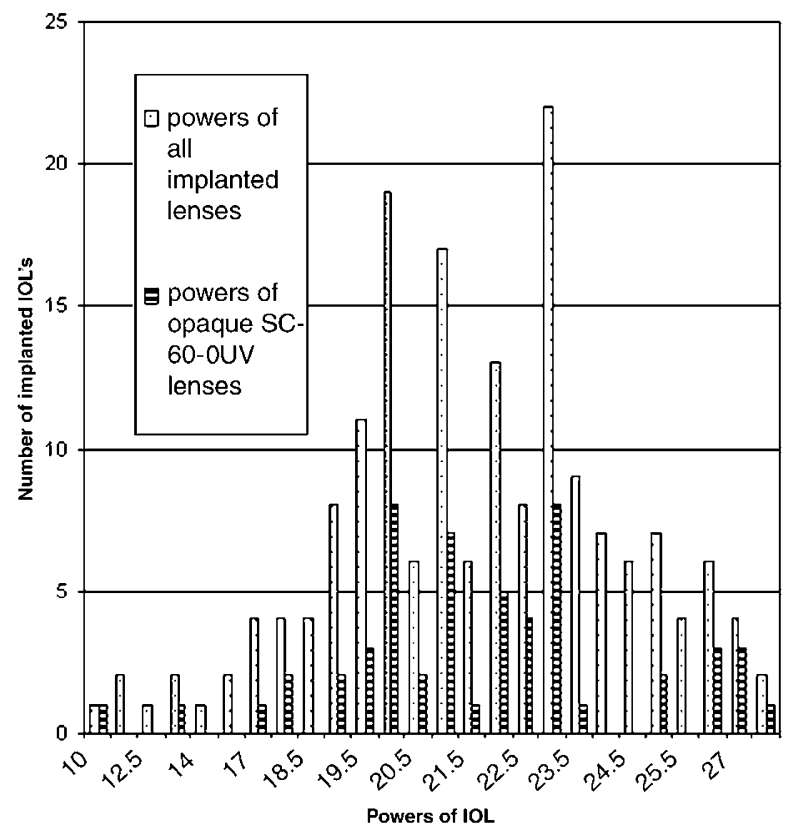

Figure 2 Chart showing almost all powers of the SC60B-0UV intraocular lens were affected.

In all, 22 patients were listed for IOL exchange, of which 16 had been performed by the time of data collection. Six surgeons (four consultant firms) were involved in IOL explantation (and exchange) procedures. Outcomes of the IOL exchange procedures are summarized in Table 1.

\section{Discussion}

Intralenticular opacification of hydrophilic acrylic IOLs may cause clinical appearances similar to a 'nuclear 


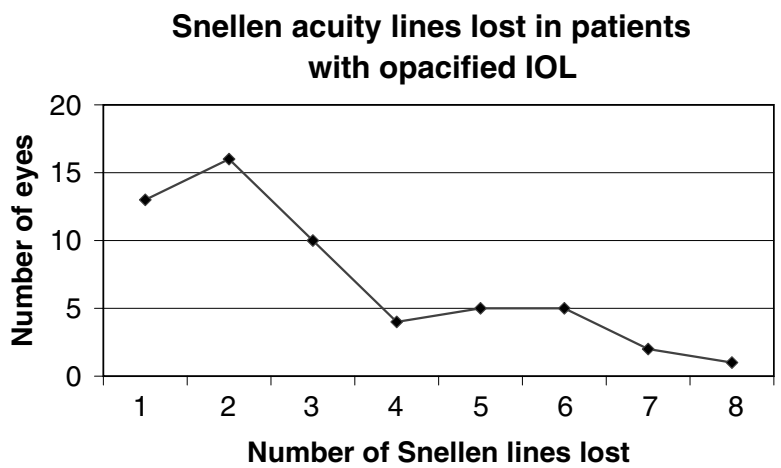

Figure 3 Chart showing loss of Snellen acuity in eyes with the opacified SC60B-0UV intraocular lenses

cataract' and is called 'pseudophakic cataract' by our colleagues. Early reports by Werner $e a^{6} l^{6}$ show a lower incidence of lens opacification at 24 months. Our data with a longer follow up (1-4 years postop) show a much higher incidence of opacification of the optic of this particular lens.

Chang $e a^{1}$ published the first clinical report of late postoperative opacification of SC-60-0UV lenses, when they reported a central clouding 7 months postoperatively, associated with a decrease in visual acuity. No inflammatory reaction was noted. Since then different causes for opacification of these lenses have been put forward. Trivedi $e t a l^{2}$ found granules in the intermediate region beneath the anterior and posterior lens surfaces. Energy-dispersive X-ray spectroscopy analysis from the same specimens revealed the presence of calcium and phosphate peaks. Frohn $e t a l^{3}$ have suggested premature ageing of the ultraviolet-blocker incorporated in the lens material to be responsible for clouding of the lens. The source of the opacification would be in the IOL material itself. Neither fatty acids nor proteins could be found within the IOLs. Interestingly, 'glistenings' in the Alcon Acrysof ${ }^{\mathrm{TM} 4}$ caused by fluid-filled vacuoles present in the Alcon acrysof $^{\mathrm{TM}}$ lens were found to be different from the granules of variable sizes found in the SC-60-0UV lenses. ${ }^{5}$ Werner $e t a l^{6}$ reported 18 cases (4.9\%) of late postoperative opacification of the SC-60-0UV lens. In our series with a longer postoperative follow-up period, we report 56 occurences of significant IOL opacification out of a total of 181 implanted lenses.

The explantation of the SC-60-0UV is not particularly difficult but poor surgical techniques by inexperienced surgeons can lead to complications that result in poor visual outcome (Table 1). The anterior capsule rim can usually be teased-off the surface of the lens (occasionally small radial cuts are required) and the lens can be manoeuvered into the anterior chamber where it can readily be cut either into two halves or $\frac{3}{4}$ across the optic for retrieval through a $3.5-4.0 \mathrm{~mm}$ incision. Attempts at rotation of the IOL out of the capsular bag can lead to zonular and posterior capsule rupture. In two of our cases, YAG laser posterior capsulotomy had been performed before lens exchange, increasing the risk of vitreous loss (one vitrectomy and one aborted IOL exchange). Results even after successful IOL exchange surgery may not be that encouraging due to higher incidence of postoperative macular oedema. Posterior capsular rupture may occur during lens exchange surgery, which may necessitate sulcus-fixated or anterior chamber IOL implant after the opacified lens is removed.

The strength of our series has been a longer postoperative period with a regular and continuing

Table 1 Outcomes of intraocular lens exchange procedures.

\begin{tabular}{|c|c|c|c|c|c|}
\hline $\begin{array}{l}\text { Patient } \\
\text { no. }\end{array}$ & $\begin{array}{l}\text { Eye } \\
\text { involved }\end{array}$ & $\begin{array}{l}\text { Preexchange } \\
\text { VA }\end{array}$ & $\begin{array}{c}\text { Postexchange } \\
\text { VA }\end{array}$ & $\begin{array}{l}\text { Position of new IOL after } \\
\text { IOL exchange }\end{array}$ & Postoperative and other comments \\
\hline 1 & Right & $6 / 36$ & $6 / 36$ & Could not be explanted & Abandoned \\
\hline 2 & Left & $6 / 9$ & $6 / 12$ & $\mathrm{PC}$ in sulcus & \\
\hline 3 & Right & $6 / 12$ & $6 / 12$ & PC in sulcus & Postexchange developed a right macular hole \\
\hline 4 & Left & $6 / 60$ & $6 / 9$ & PC in bag & Developed macular oedema postop \\
\hline 5 & Left & $6 / 18$ & $6 / 6$ & PC in bag & \\
\hline 6 & Right & $6 / 9$ & CF & Could not be explanted & Abandoned. ARMD \\
\hline 7 & Left & $6 / 9$ & $3 / 60$ & $\mathrm{PC}$ in bag & PC plaque. Glaucoma \\
\hline 8 & Left & $6 / 36$ & $6 / 24$ & AC lens & Anterior vitrectomy. AC IOL \\
\hline 9 & Right & $\mathrm{CF}$ & $6 / 60$ & AC lens & $\mathrm{R}$ macular oedema postop \\
\hline 11 & Right & $6 / 60$ & $6 / 60$ & Could not be explanted & Abandoned. ARMD, DR \\
\hline 12 & Left & $6 / 12$ & & PC in bag & \\
\hline 13 & Left & $6 / 60$ & $6 / 6$ & $\mathrm{PC}$ in sulcus & \\
\hline 14 & Right & $6 / 9$ & $6 / 36$ & PC in sulcus & $\begin{array}{l}\text { Glaucoma. Patient developed postop macular } \\
\text { oedema and endothelial decompensation }\end{array}$ \\
\hline 15 & Right & $6 / 9$ & $6 / 9$ & PC in bag & \\
\hline 16 & Left & $6 / 24$ & $6 / 18$ & PC in sulcus & \\
\hline 17 & Left & $6 / 36$ & $6 / 6$ & PC in bag & Glaucoma \\
\hline
\end{tabular}


follow-up. However, the limitations have been the retrospective nature of study, multiple observers making clinical notes and absence of a grading of IOL opacification. The retrospective nature did not allow an objective quantitative measurement of the implant opacification that emerged over time. The need for lens exchange was assessed individually on the basis of the patient's subjective perception of their quality of vision in the presence of an opacified IOL. Thus, some patients with relatively good Snellen acuity were dissatisfied with their vision presumably due to decreased contrast sensitivity. With such criteria, 22 patients $(12 \%)$ were judged in need of a lens exchange. The lens exchange procedures showed inconsistent results due to different surgeons with different levels of surgical skills.

We continue to monitor these patients with visual impairment due to failure of a prosthetic device (IOL).

It is estimated that about 75000 of these IOLs have been implanted worldwide before its withdrawal from the market in June 2000. If our opacification rate of $31 \%$ with follow-up of 4 years is a true reflection of the SC60B-0UV performance after implantation, there should be currently a far greater number of patients than hitherto expected with suboptimal results following cataract surgery. It is possible that few of these cases are now being reported as the occurrence of this phenomenon is widely recognized and the IOL in question has been withdrawn. However, the scale of the problem may be greater than originally thought. This episode emphasizes the need for care and attention when introducing new technology into our medical and surgical practices.

\section{References}

1 Chang BYP, Davey KG, Gupta M, Hutchison C. Late clouding of an acrylic lens following routine phacoemulsification. Eye 1999; 13: 807-808.

2 Trivedi RH, Werner L, Apple DJ, Pandey SK, Izak AM. Postcataract-intraocular lens (IOL) surgery opacification. Eye 2002; 16: 217-241.

3 Frohn A, Dick B, Augustin AJ, Grus FH. Late opacification of the foldable hydrophilic acrylic lens SC-60B-0UV. Ophthalmology 2001; 108: 1999-2004.

4 Dhaliwal DK, Mammalis N, Olson RJ, Crandall AS, Zimmerman P, Alledredge OC et al. Visual significance of glistenings seen in the acrysof intraocular lens. J Cataract Refract Surg 1996; 22: 452-457.

5 Izak Am, Werner L, Pandey SK, Apple DJ. Calcification of modern foldable hydrogel intraocular lens designs. Eye 2003; 17: 393-406.

6 Werner L, Apple D, Kaskalologlu, Pandey S. Dense opacification of the optical component of a hydrophilic acrylic intraocular lens: a clinicopathological analysis of 9 explanted lenses. J Cataract Refract Surg 2001; 27: 1485-1492. 